\title{
On the transition between heterogeneous and homogeneous freezing
}

\author{
K. Gierens \\ Deutsches Zentrum für Luft- und Raumfahrt, Institut für Physik der Atmosphäre, Oberpfaffenhofen, Germany \\ Received: 14 October 2002 - Published in Atmos. Chem. Phys. Discuss.: 16 December 2002 \\ Revised: 10 March 2003 - Accepted: 24 March 2003 - Published: 15 April 2003
}

\begin{abstract}
Box model simulations of an uplifting and adiabatically cooling cloud of aerosol have been performed in order to study the transition between cirrus formation dominated by homogeneous nucleation of ice to that dominated by heterogeneous nucleation. The aerosol was assumed to consist of an internal mixture of sulfuric acid solution droplets with inclusions of soot. The parametrisation of DeMott et al. (1997) was used to simulate the heterogeneous nucleation of ice in such droplets with soot inclusions. The simulations show that the transition from heterogeneous to homogeneous nucleation occurs over a narrow range of soot concentration. Thus it seems to be possible to fix critical concentrations of heterogeneous ice nuclei which must be exceeded if heterogeneous freezing dominates cirrus formation. A formula has been derived that allows to compute the critical concentrations of heterogeneous ice nuclei as a function of temperature, updraft speed, ambient pressure, and supersaturation at which heterogeneous freezing occurs. Generally, homogeneous nucleation dominates in regions with updrafts stronger than $20 \mathrm{~cm} \mathrm{~s}^{-1}$, with the exception of heavily polluted areas which could be common in the northern hemisphere due to air traffic, where updrafts of the order $1 \mathrm{~m} \mathrm{~s}^{-1}$ may be necessary to render heterogeneous nucleation unimportant. According to the present results it cannot be excluded that heterogeneous nucleation plays a more important role for cirrus formation in the northern midlatitudes than anywhere else. A possible consequence of these results is that air pollution may lead to a higher coverage of cirrus clouds, but then these clouds will be optically thinner than clouds formed by homogeneous freezing, with the exception of regions where condensation trails are frequent.
\end{abstract}

Correspondence to: K. Gierens (klaus.gierens@ dlr.de)

\section{Introduction}

Cirrus clouds in the cold upper troposphere $\left(T \lesssim-40^{\circ} \mathrm{C}\right)$ are generally thought to form mainly by homogeneous freezing of aqueous solution droplets (e.g. Sassen and Dodd, 1988; Heymsfield and Sabin, 1989; Heymsfield and Miloshevich, 1993). When there is enough background aerosol present, homogeneous nucleation is a thermodynamically controlled process, that is, it takes place when a critical supersaturation (dependent on temperature) is reached in an airmass. It has been shown in the laboratory by Koop et al. (2000) that the critical supersaturation is independent of the chemical nature of the aerosol. Gierens et al. (2000), comparing and correlating data of ice-supersaturation from MOZAIC, Measurement of Ozone from Airbus-in-Service Aircraft (Marenco et al., 1998), of subvisible cirrus from SAGE II, Stratospheric Aerosol and Gas Experiment II (Wang et al., 1996), and of thermodynamic conditions for cirrus formation from re-analysis data of the European Centre for Medium Range Weather Forecast (Sausen et al., 1998), could show that cirrus formation seems to be thermodynamically controlled in the tropics and in the southern midlatitudes upper troposphere, but not in the same way in the northern midlatitudes, where the thermodynamic control is much weaker. These hemispheric differences may partly reflect differences between statistical distributions of vertical wind speed between tropics, and southern and northern hemisphere ( $\mathrm{SH}$ and $\mathrm{NH}$ ). Even if the mean updraft speeds are similar in both hemispheres, the variances will probably be significantly larger in the $\mathrm{NH}$ than in the $\mathrm{SH}$, because of the orographic excitation of vertical motion in the NH. This is supported by the stronger instantaneous temperature fluctuations (on a spatial scale of $300 \times 300 \mathrm{~km}^{2}$ ) in the NH compared to the tropics that has been found from MOZAIC data (Gierens et al., 1997). Obviously, threshold conditions for ice formation can be met more often in regions of stronger fluctuations of vertical wind speeds than in calmer regions when the mean 
(large scale) thermodynamic conditions are similar in both regions. However, the hemispheric differences of thermodynamic control of cirrus formation can also suggest that the composition of the freezing aerosol has a more important effect in the polluted northern hemisphere compared to the cleaner regions of the world. Since homogeneous nucleation seems not to depend on the aerosol composition one may conclude that then heterogeneous processes must play a bigger role for cirrus formation in the northern midlatitudes. Such heterogeneous effects could be brought about inter alia by aircraft soot emissions. Indeed, Ström and Ohlsson (1998) found that cirrus ice crystals in a region of heavy air traffic (southern Germany) often contain some kind of "absorbing material" (probably soot), and moreover such inclusions were most frequent in those altitudes where the air routes are concentrated $(8-12 \mathrm{~km})$.

The notion "heterogeneous nucleation" is a collective term for various physical mechanisms that may occur in the atmosphere (see Vali, 1985, for a definition of the terminology). Deposition nucleation requires the presence of dry solid particles, whose existence in the upper troposphere has not been shown so far (DeMott et al., 1997). Contact freezing, requiring the presence of an external mixture of solid and liquid particles, is probably unimportant for cirrus clouds because it seems to be suppressed in updrafts and the collection rates are very small for typical aerosol particle sizes in the upper troposphere (Young, 1993, chapter 4.5.3). The two remaining mechanisms, condensation and immersion freezing require an internal mixture of aerosol, that is, solid particles immersed in a liquid coating.

Although pure graphitic soot is hydrophobic, soot particles from other sources, in particular from combustion, may act as heterogeneous ice nuclei, probably because of various contaminations on their surface. This has first been shown by DeMott (1990) in the laboratory for temperatures between $-25^{\circ} \mathrm{C}$ and $-40^{\circ} \mathrm{C}$. More recent laboratory experiments of DeMott et al. (1999) explored a lower temperature regime that is more representative for the upper troposphere. It could be shown that below $-53^{\circ} \mathrm{C}$ soot particles with a substantial amount of sulfuric acid solution on their surface (several monolayers) induce ice formation at supersaturations below the critical supersaturations necessary for homogeneous nucleation. Such an aerosol may be generated by aviation since jet engines emit about $10^{15}$ soot particles and about $10^{15}$ to $4 \times 10^{17}$ volatile aerosol particles larger than about $5 \mathrm{~nm}$ in diameter per kg kerosene burnt, in particular sulfuric acid solution droplets (Fahey and Schumann, 1999; Schumann, 2002, and references therein). It is thus conceivable that aircraft emissions can lead to soot particles that are immersed in a coating of sulfuric acid solution. However, it must be said that an understanding of the very physical process that induces the freezing at or around the soot particles is still lacking. For instance, soot from various sources (combustion soot, Degussa soot, sparc generator soot, etc.) behave differently in freezing experiments, yet the exact reasons for these differences are unknown. One must also admit that it is not possible or justified at the current state of knowledge to define a critical supersaturation at which heterogeneous freezing of soot would commence.

Thus, heterogeneous nucleation is still a closed book in many respects, but it may have important effects on cirrus clouds. Jensen and Toon (1997) performed numerical simulations of cirrus formation in slow updrafts and showed that the presence of soot can not only enlarge the fractional cover of cirrus clouds, but it can also alter the properties of the cirrus rather dramatically compared to a case when only sulfate aerosol was assumed to be present. Kristensson et al. (2000) measured reductions of effective crystal diameters by $10-30 \%$ in cirrus perturbed by aviation (as indicated by the "absorbing material" in the crystals, see Ström and Ohlsson, 1998).

Although experimental evidence is lacking that aviation and other anthropogenic aerosol indeed affects cirrus formation and cirrus cloud cover, the weak thermodynamic control of cirrus formation in the northern midlatitudes gives reason to study such potential effects both experimentally and by modelling. Since heterogeneous and homogeneous freezing can act simultaneously in the atmosphere it is useful to derive criteria which tell one which of the two freezing modes is dominant in a given situation. This will of course depend on the concentration of heterogeneous ice nuclei, that is on the number of aerosol particles that heterogeneously induce ice crystal formation at a supersaturation below the critical supersaturation for homogeneous nucleation. I will show that it is possible to determine a critical concentration of such ice nuclei, below of which homogeneous nucleation dominates, while heterogeneous nucleation takes over the dominant role at higher ice nucleus concentrations. The study has been perfomed by means of simple box model simulations where sulfuric acid solution droplets with inclusions of soot served as heterogeneous ice nuclei. Additionally, I will derive a simple analytical formula for the calculation of the critical concentration of heterogeneous ice nuclei as a function of supersaturation necessary for heterogeneous freezing, temperature, updraft speed, and pressure. This formula can be used in large scale models for the control of a switch between the two nucleation modes.

\section{The box model}

A simple box model with bulk microphysics was employed for this study which simulates the evolution of an aerosol cloud in uplifting and cooling air. Prognostic variables are aerosol and ice crystal number densities, ice mass and vapour mass concentration, and temperature. The updraft yields an adiabatic cooling of $9.77 \times 10^{-5} \mathrm{~K} \mathrm{~s}^{-1}$ per $1 \mathrm{~cm} \mathrm{~s}^{-1}$ of updraft velocity. The aerosol is an internal mixture of aqueous solution droplets of sulfuric acid with or without insoluble inclusions of soot. A log-normal size distribution is assumed 
for the "dry" aerosol (that is, the pure sulfuric acid) with a geometrical mode radius of $10 \mathrm{~nm}$ and geometrical standard deviation $\sigma_{a}$ of 1.48. The fraction of aerosol droplets bearing an inclusion, $S N F$ (i.e. soot number fraction), the soot mass fraction (relative to the mass of the sulfuric acid in the droplet) of a soot including aerosol particle, $S M F$, and the number concentration of aerosol particles, $N_{a}$, are free parameters. The soot mass fraction can be translated into a soot surface, assuming a specific soot surface (i.e. surface per unit mass) of $\Omega_{m}=7.5 \times 10^{5} \mathrm{~cm}^{2} \mathrm{~g}^{-1}$ (Kärcher et al., 1996). ${ }^{1}$ Assuming a direct proportionality between mass (i.e. volume) and surface of aircraft (kerosene) soot is an expression for the fractal nature of this kind of soot.

With the given parameters, $S N F, S M F$, and $N_{a}$, and assuming the log-normal size distribution of the "dry" aerosol, the soot concentration (i.e. mass of soot per unit volume of air) is given by

$C_{\text {soot }}=N_{a} \cdot S N F \cdot S M F \cdot(4 \pi / 3) \rho_{a} M_{3}$,

where $\rho_{a}$ is the density of pure sulfuric acid, and

$M_{3}=r_{a}^{3} \exp \left[(9 / 2)\left(\ln \sigma_{a}\right)^{2}\right]$

is the third moment of the aerosol size distribution. Alternatively, the soot concentration can be translated into the total soot surface density $\Omega_{V}$ (soot surface per unit volume of air), i.e.

$\Omega_{V}=\Omega_{m} C_{\text {soot }}$

The density of sulfuric acid depends slightly on temperature, it varies from $\rho_{a}=2.09 \mathrm{~g} \mathrm{~cm}^{-3}$ at $-35^{\circ} \mathrm{C}$ to $2.22 \mathrm{~g} \mathrm{~cm}^{-3}$ at $-70^{\circ} \mathrm{C}$. All other quantities in the formulae for $C_{\text {soot }}$ and $\Omega_{V}$ are independent of temperature.

As stated above, it is unknown how the ice formation process on the surfaces of soot particles works. Therefore, I make the same working hypothesis as DeMott et al. (1997), who extrapolated the laboratory results for temperatures higher than $-40^{\circ} \mathrm{C}$ to lower temperatures and replaced the temperature of pure water droplets by an effective freezing temperature $T_{\text {eff }}$ of aqueous solution droplets. Although I do not know whether the soot in the atmosphere actually behaves as this working hypothesis assumes, I think that such a procedure is justified as long as the study aims at how the transition between homogeneous and heterogeneous paths looks like. It is not the aim of these simulations to determine the exact critical soot concentration where the transition takes place. Such a determination must await better knowledge of the physical processes that occur on the soot surface.

The parameterisation of DeMott et al. (1997) uses a number of active sites for formation of an ice embryo per unit surface of soot. This is a very strong function of the effective freezing temperature, namely:

surface number density of active sites $=A\left(-T_{\mathrm{eff}}\right)^{B}$,

\footnotetext{
${ }^{1}$ More recent values of $\Omega_{m}$ are higher, up to $4 \times 10^{6} \mathrm{~cm}^{2} \mathrm{~g}^{-1}$.
}

with $A=1.04 \times 10^{-4} \mathrm{~cm}^{-2}$ and $B=7.767$.

While cooling, the aerosol may freeze heterogeneously due to their soot inclusions or homogeneously. Aerosol droplets without inclusions can only freeze by homogeneous nucleation while those with inclusions can freeze via both mechanisms (which means that the sulfuric acid solution in such a droplet can ignore the presence of the inclusion). For the droplets with inclusions the model chooses the freezing pathway with the higher nucleation rate in each timestep. Homogeneous freezing is parameterised in the box model following Koop et al. (2000). The integration over the size distribution is performed via a numerical Gauß-Hermite integration as described by Gierens and Ström (1998). This gives for each timestep the fraction of aerosol particles that freeze. The freshly formed ice crystals begin to grow by vapour deposition, thereby reducing the supersaturation. The depositional crystal growth is parameterised as in Koenig (1971), i.e. $d m / d t=a m^{b}$, with crystal mass $m$, and temperature dependent parameters $a, b$, which are listed for temperatures below $-40^{\circ} \mathrm{C}$ by Gierens (1996).

All simulations run from an initial temperature $T=$ $-53^{\circ} \mathrm{C}$ or lower. This temperature was a threshold in laboratory experiments of DeMott et al. (1999), below which soot particles enclosed in thick coatings of sulfuric acid solution got effective as heterogeneous ice nuclei at supersaturation below that necessary for homogeneous nucleation. The initial relative humidity was $70 \%$ with respect to liquid water $(R H)$, or $116 \%$ with respect to ice $\left(R H_{i}\right)$ at $T=-53^{\circ} \mathrm{C}$ and $50 \%\left(R H_{i}=96 \%\right)$ at $T=-73^{\circ} \mathrm{C}$.

\section{Results and discussion}

Figure 1 shows a typical outcome of a boxmodel simulation with the internally mixed aerosol. The temperature-axis can be read as a reversed time-axis, with time progressing to the left. Displayed is the number concentration of ice crystals that form in the cooling aerosol cloud. The curves of Fig. 1 are computed for an updraft velocity of $10 \mathrm{~cm} \mathrm{~s}^{-1}$, a number concentration of aerosol particles of $3 \times 10^{8} \mathrm{~m}^{-3}$, and a soot mass fraction $S M F=0.1$. The soot number fraction $(S N F)$ is used as a curve parameter. The curve with $S N F=0.1$ shows the form typical for heterogeneous nucleation only. Nucleation starts at about $-54.5^{\circ} \mathrm{C}$ and proceeds on down to about $-55.5^{\circ} \mathrm{C}$ where the growth of the ice crystals has consumed enough water vapour to quench the nucleation. Simulations with higher $S N F$ generally yield a similar behaviour (not shown), although they result in higher final ice crystal concentrations. The curve with $S N F=0.03$ already shows strong signs of homogeneous nucleation at $T<-55.5^{\circ} \mathrm{C}$ where the crystal number density suddenly jumps up by a factor of approximately seven. Heterogeneous nucleation produces some ice crystals between $-54.5^{\circ} \mathrm{C}$ and $-55.5^{\circ} \mathrm{C}$, but their number is too low for consuming the supersaturation; hence homogeneous nucleation takes over 


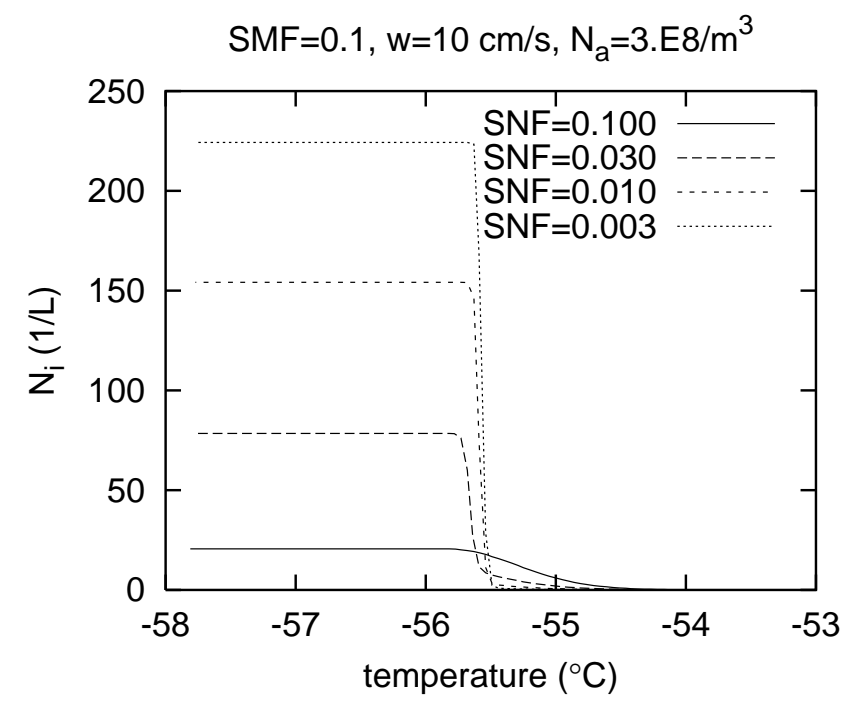

Fig. 1. Number density of ice crystals forming from internally mixed aerosol of sulfuric acid solution with soot inclusions in a uplifting and adiabatically cooling airmass as function of temperature (which may be considered a reverse time axis) as simulated in a box-model. Ice crystals form by heterogeneous and homogeneous nucleation. The simulations were performed with $10 \mathrm{~cm} / \mathrm{s}$ uplift, with soot mass fraction $S M F=0.1$ (of those aerosol droplets that bear an inclusion), total aerosol number density $N_{a}=3 \times 10^{8} \mathrm{~m}^{-3}$, and with fraction of aerosol particles bearing an inclusion, $S N F$, as indicated on the figure. Homogeneous nucleation is signalled by the steep increase of $N_{i}$ with decreasing temperature.

crystal production at $-55.5^{\circ} \mathrm{C}$. The next curve with $S N F=$ $0.01\left(\Omega_{V}=4.1 \times 10^{-9} \mathrm{~cm}^{2} \mathrm{~L}^{-1}\right)$ is similar to the previous one but shows the characteristics of homogeneous nucleation even more. The fourth curve with $S N F=0.003$ $\left(\Omega_{V}=1.2 \times 10^{-9} \mathrm{~cm}^{2} \mathrm{~L}^{-1}\right)$ shows homogeneous nucleation almost exclusively on this plot with linear $N_{i}$-axis, in particular the sudden and steep increase on $N_{i}$ with decreasing temperature. Further decrease of $S N F$ yields nearly congruent curves as the one for the latter $S N F$-value shown here. It is noteworthy that the transition between the first sign of homogeneous nucleation and full homogeneous nucleation occurs within about one order of magnitude of $S N F$-values, viz. between about 0.03 and 0.003 for the present case. This implies also that the transition between freezing dominated by heterogeneous nucleation and freezing dominated by homogeneous nucleation spans an order of magnitude of the total soot concentration. For the parameterisation of DeMott et al. (1997) that we use here, the critical concentration for the simulations of Fig. 1 is about $0.01 \mathrm{ng} \mathrm{m}^{-3}$ (please recall that this number makes only sense within the framework of our working hypothesis, namely that the results of DeMott (1990) can be extrapolated to lower temperatures).

Additional series of simulations were performed with the same initial conditions as so far, but with changed values of $S M F$ (increased to 0.5 ) and $N_{a}$ (decreased by an order of

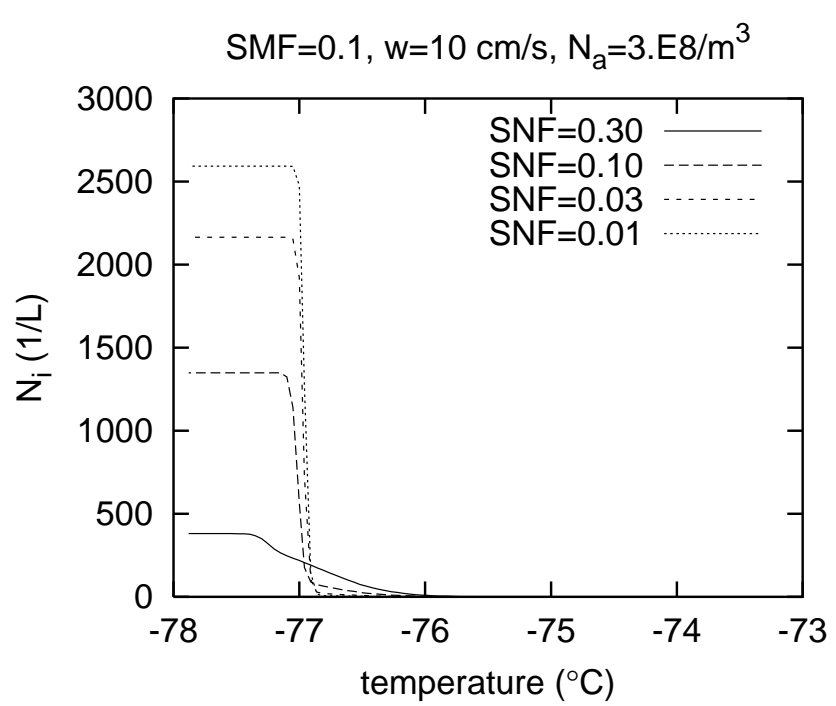

Fig. 2. As Fig. 1, but computed with initial temperature of $-73^{\circ} \mathrm{C}$ and initial relative humidity $R H=50 \%$.

magnitude to $3 \times 10^{7} \mathrm{~m}^{-3}$ ). These simulations resulted in qualitatively similar curves $N_{i}$ vs. $T$ (i.e. vs. time), and the transition between heterogeneous and homogeneous nucleation occurred at the same characteristic soot concentration as before (not shown). Variation of the geometric mean radius from $10 \mathrm{~nm}$ to $100 \mathrm{~nm}$, and a variation of the geometric standard deviation from 1.2 to 2.0 yields similar results, i.e. the transition between the two freezing modes takes place over an order of magnitude in soot concentration that can be fixed at a certain critical value, and the latter does not depend noticably on the size distribution of the aerosol.

The simulations up to now were all performed with the same initial temperature, such that the number density of active sites for nucleation in the parametrisation of DeMott etal. (1997) was the same for the same soot concentration. The potential role of the number of active sites for the transition between the two nucleation modes could therefore not become effective. Figure 2 shows a set of simulations performed with initial temperature of $-73^{\circ} \mathrm{C}$ and initial relative humidity of $50 \%$. Soot mass fractions and aerosol number density are the same as in Fig. 1, but the soot number fractions are higher by about a factor of three. First one may note, that at this low temperature much more crystals are formed than in the warmer case of Fig. 1. The reason for this is the decreasing growth rate of single crystals with decreasing temperature. Thus the consumption of supersaturation proceeds slowly and the nucleation processes can act longer and at a higher rate, producing more crystals than in the warmer case. This effect has been observed earlier in simulations by Jensen and Toon (1994). Second, one observes that already the curve for $S N F=0.3$ bears signs of homogeneous nucleation, such that in this case the critical soot concentration is one order of magnitude larger (i.e. 


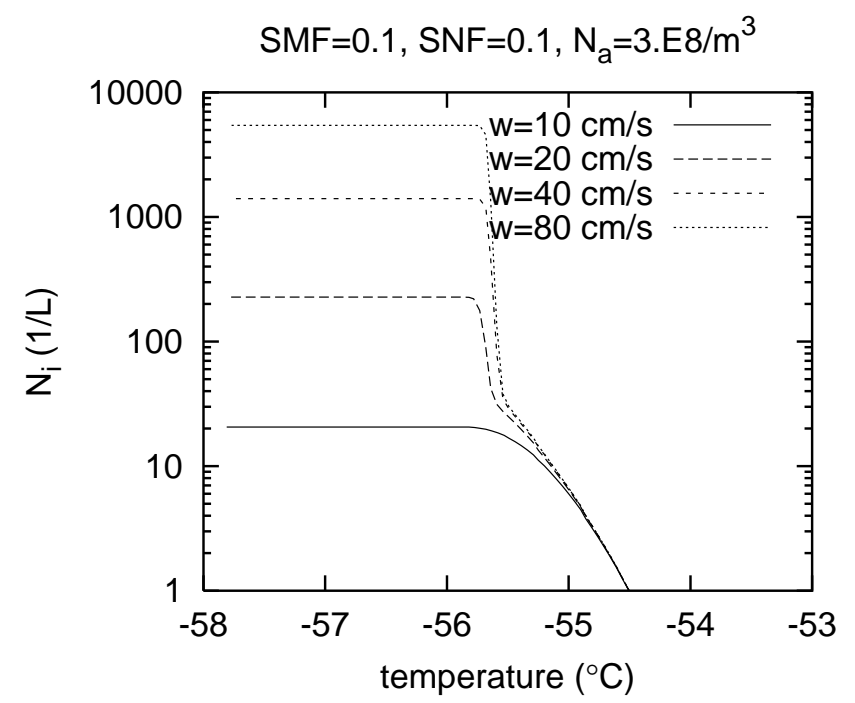

Fig. 3. As Fig. 1, but with fixed soot number fraction of 0.1 , and updraft velocity $w$ as curve parameter, and with logarithmic y-axis. The solid curve for $w=10 \mathrm{~cm} \mathrm{~s}^{-1}$ is identical to the solid curve in Fig. 1. This is the only case that shows no indications of homogeneous nucleation. All other cases with higher updraft velocities show effects of homogeneous nucleation that become stronger with increasing updraft speed.

$\approx 0.1 \mathrm{ng} \mathrm{m}^{-3}$ ) than in the simulations shown above. This happens although the surface number density of active sites for heterogeneous nucleation increases itself by a factor of ten between the two sets of experiments. In order to compute this factor it is sufficient to consider the lowest effective temperature achieved during an experiment since this marks the time when the nucleation rate peaks. In the former experiments that started at $T=-53^{\circ} \mathrm{C}$ the minimum effective temperature was $-39^{\circ} \mathrm{C}$ while it is $-52.5^{\circ} \mathrm{C}$ in the latter experiments where cooling started from $T=-73^{\circ} \mathrm{C}$. The ratio of the number density of active sites for heterogeneous nucleation is therefore $(52.5 / 39)^{B}=10.06$ (see Eq. 4). Thus we find that at $T=-73^{\circ} \mathrm{C}$ it needs about 100 times more active nucleation sites to suppress homogeneous nucleation than at the higher temperature of $T=-53^{\circ} \mathrm{C}$. Anticipating the results of the following section, one can attribute the increase of the critical soot concentration with decreasing temperature to (a) the decrease of the diffusion coeffient for water molecules in air, (b) the decrease of the saturation vapour pressure with decreasing temperature.

Finally, the updraft velocity is an important parameter that has to be considered. Previous simulations that took both nucleation modes into account (e.g. DeMott et al., 1997; Spice et al., 1999; Sassen and Benson, 2000) agree concluding that heterogeneous nucleation becomes relatively unimportant for updrafts exceeding a few $10 \mathrm{~cm} \mathrm{~s}^{-1}$. This expectation is essentially confirmed by the results of the present model. Simulations were performed with $S M F=0.1, S N F=0.1$,

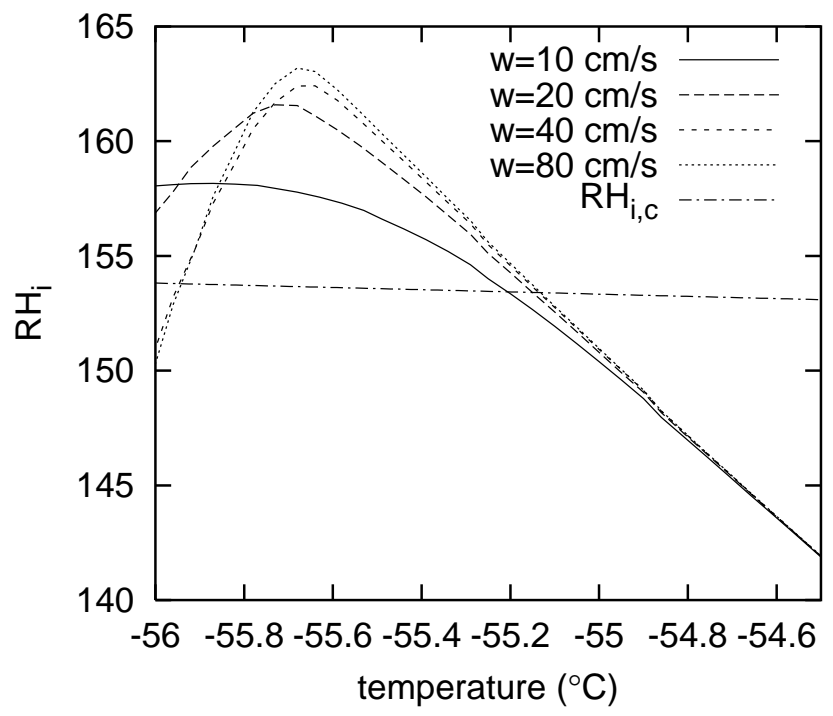

Fig. 4. Relative humidity with respect to ice, $R H_{i}$ versus temperature (i.e. vs. time) for the box model simulations of Fig. 3, with updraft speed as curve parameter. The dash-dotted nearly horizontal line labelled " $R H_{i, c}$ " is the critical relative humidity for homogeneous nucleation. It is seen that the supersaturation becomes higher for increasing updraft velocities. Although the critical relative humidity for homogeneous nucleation is surpassed in all cases, this process in unimportant in the case with $w=10 \mathrm{~cm} \mathrm{~s}^{-1}$. However in all other cases it dominates.

$N_{a}=3 \times 10^{8} \mathrm{~m}^{-3}$, and with initial temperature of $-53^{\circ} \mathrm{C}$. The run with $10 \mathrm{~cm} \mathrm{~s}^{-1}$ updraft was shown in Fig. 1 as a case that is dominated by heterogeneous nucleation. Additional runs with updrafts of 20,40 , and $80 \mathrm{~cm} \mathrm{~s}^{-1}$ show increasing signs of homogeneous nucleation, as demonstrated in Fig. 3. Since the soot concentration is the same in all these simulations, this parameter cannot decide here whether or not homogeneous nucleation is suppressed. The crucial quantity is the temporal evolution of ice-supersaturation. This is shown in Fig. 4, where also the critical relative humidity for homogeneous nucleation, $R H_{i, c}$, (Koop et al., 2000; Kärcher and Lohmann, 2002) is plotted versus temperature. The figure shows that in the only case that is dominated by heterogeneous nucleation, the supersaturation does not reach as high values than in the other cases. Although $R H_{i, c}$ is surpassed, the homogeneous nucleation rate for $w=10 \mathrm{~cm} \mathrm{~s}^{-1}$ remains low. The supersaturation in the other cases reaches higher values in spite of the fact that the number of crystals formed by heterogeneous nucleation at the moment when $R H_{i}=R H_{i, c}$ increases with updraft speed. Obviously the consumption of water vapour by growing ice crystals cannot halt the increase of supersaturation by cooling of the air in an updraft of $w \gtrsim 20 \mathrm{~cm} \mathrm{~s}^{-1}$, at least for the case considered here. The same result applies when other combinations of $S N F$ and SMF are tried, such that the soot concentration remains the same. A corresponding set of simulations with ini- 


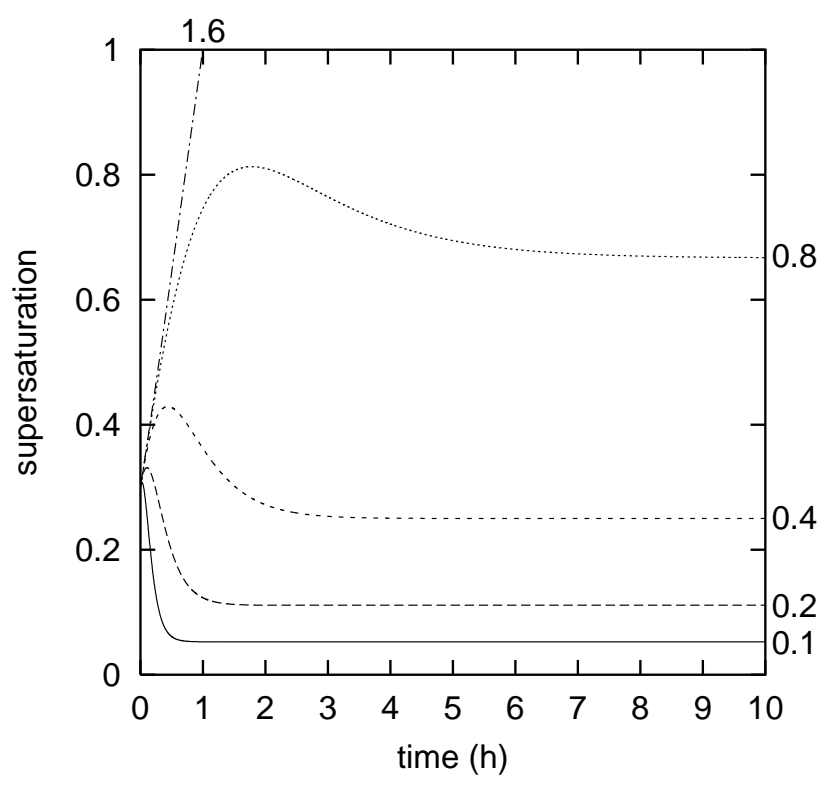

Fig. 5. Typical time histories of supersaturation in a cirrus cloud formed heterogeneously at initial supersaturation of 0.3 , and situated in an airmass uplifting at about $10 \mathrm{~cm} / \mathrm{s}$, such that the updraft time scale $\tau_{u}$ is $2 \mathrm{~h}$. Curves are shown for various growth time scales, given as curve parameters (in hours).

tial temperature of $-73^{\circ} \mathrm{C}$ and with $S N F=0.3$ (not shown) also leads to the same result, namely that homogeneous nucleation is dominant for $w \gtrsim 20 \mathrm{~cm} \mathrm{~s}^{-1}$. However, homogeneous nucleation can be suppressed even in strong updrafts when very high soot contamination of the aerosol is assumed. For example, a test simulation with $S N F=1$ at $-53^{\circ} \mathrm{C}$ initial temperature (other parameters unchanged) showed no homogeneous nucleation up to at least $w=40 \mathrm{~cm} \mathrm{~s}^{-1}$, and in another one where additionally $S M F$ was increased to 0.5 , heterogeneous nucleation dominated still at $w=80 \mathrm{~cm} \mathrm{~s}^{-1}$, and it was necessary to increase $w$ to $1.5 \mathrm{~m} \mathrm{~s}^{-1}$ in order to get a substantial contribution by homogeneous nucleation to ice formation. Such heavily polluted cases can principally occur nowadays in the upper troposphere of the northern midlatitudes as a result of aviation emissions (Rahmes et al., 1998).

\section{Analytical approach}

The latter observation of the previous section, namely that the time evolution of relative humidity (or supersaturation) is the crucial point to determine whether homogeneous nucleation will dominate cirrus formation in an uplifting airmass that contains a number of heterogeneous ice nuclei (nuclei that undergo heterogeneous freezing at a supersaturation below the critical one for homogeneous freezing), allows to derive a simple estimate of the critical concentration of heterogeneous ice nuclei, which would suffice to suppress homogeneous nucleation. This can be done by considering the tem- poral evolution of the supersaturation after a number of ice crystals have formed heterogeneously at a supersaturation $s_{0}$. Of course, $s_{0}$ is assumed to be smaller than the critical supersaturation for homogeneous freezing. For the sake of simplicity I assume that there is only one kind of heterogeneous ice nuclei present, all of which freeze at $s_{0}$.

Let us assume that the heterogeneous ice nuclei freeze at initial supersaturation $s_{0}$. Then the supersaturation changes with time due to crystal growth (deposition) and due to further cooling by updraft (and possibly other diabatic processes changing temperature, hence changing the saturation vapour pressure $e^{*}$ ). Thus we have

$$
\begin{aligned}
& \frac{d s}{d t}=\frac{d}{d t}\left(\frac{e-e^{*}}{e^{*}}\right) \\
& =\frac{1}{e^{*}} \frac{d e}{d t}-(1+s) \frac{d \ln e^{*}}{d t}=-\frac{c(t)}{e^{*}}-(1+s) \frac{L}{R_{v} T^{2}} \frac{d T}{d t},(5)
\end{aligned}
$$

where $L$ is latent heat of sublimation, $R_{v}$ is the gas constant of water vapour. In the latter expression I have neglected the expansion effect on an uplifting air parcel, the time scale of which $(|H / w|$ with scale height $H \approx 6500 \mathrm{~m})$ is of the order $10^{4}$ to $10^{6} \mathrm{~s}$. This is much longer than both the growth and updraft time scales discussed below. $c(t)$ is the time dependent deposition rate, for which the following ansatz is possible:

$c(t)=\left(e-e^{*}\right) / \widetilde{\tau_{g}}(t)$,

with a time dependent growth time scale $\widetilde{\tau_{g}}(t)$. The growth of ice crystals begins very slowly, when the ice crystals are initially still very small. Only later the nominal growth time scale (Kärcher and Lohmann, 2002)

$\tau_{g}=\left[(4 \pi / 3) N D r_{0}\right]^{-1}$,

is reached, with diffusion coefficient $D$ and number concentration of ice crystals $N . r_{0}$ is the radius of ice crystals that they assume after transfer of the initial supersaturation $s_{0}$ into the solid phase. Thus I parameterise $\widetilde{\tau_{g}}(t)$ as

$\tilde{\tau_{g}}(t)=\tau_{g} /\left[1-\exp \left(-b t / \tau_{g}\right)\right]$,

where $b$ is a small number of the order 1 , that depends on temperature. For the following calculations I simply set $b=$ 1. With this parameterisation the condensation rate is very small initially when the ice crystals begin to grow, thereafter $c(t)$ increases and reaches a maximum value, and it decreases again when the supersaturation is consumed. The cooling by updraft can be formulated as

$d T / d t=\Gamma w \quad$ with $\quad \Gamma=-g / c_{p}$,

with gravitational acceleration $g$ and specific heat of dry air $c_{p}$. Introducing an updraft timescale

$\tau_{u}=\left(R_{v} c_{p} T^{2}\right) /(L g w)$ 

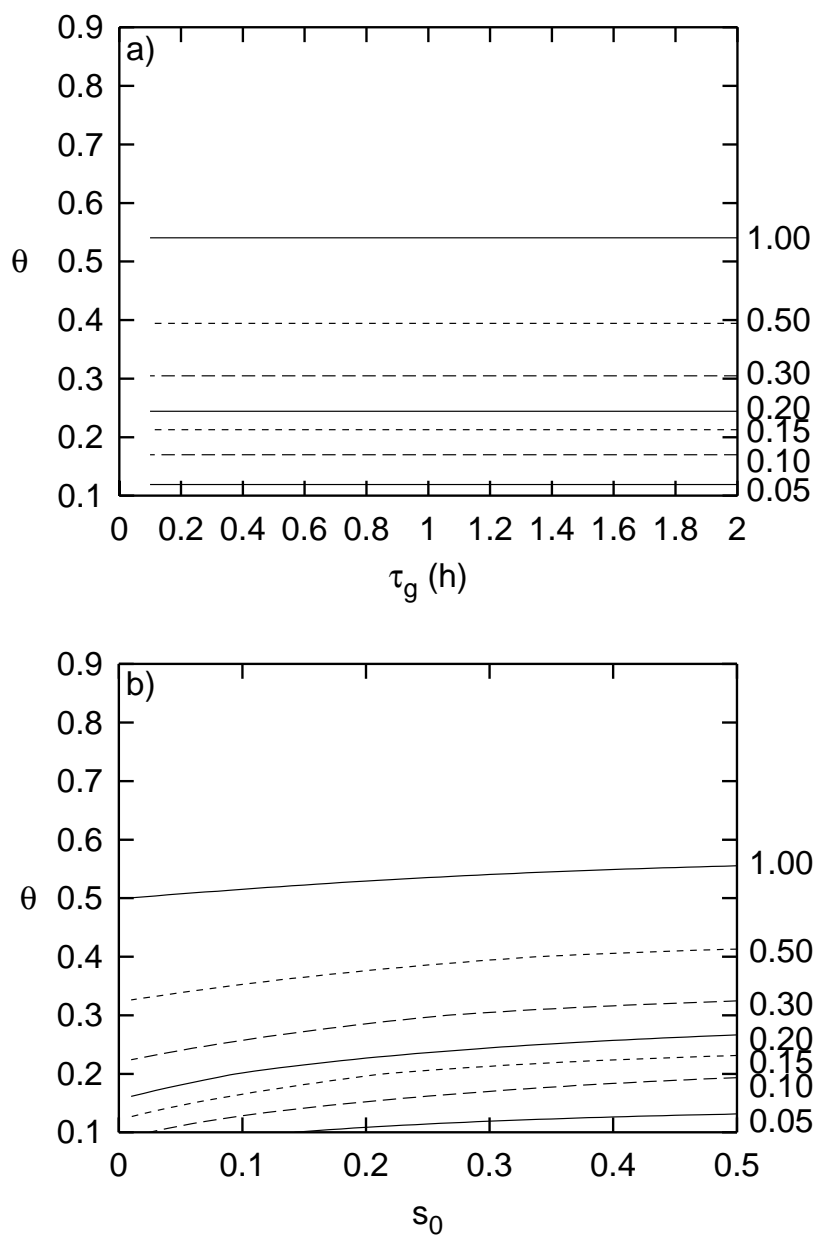

Fig. 6. Panel a): $s_{\max }-s_{0}$ (given as curve parameter) as a function of growth time scale $\tau_{g}$ (in hours) and the ratio $\theta=\tau_{g} / \tau_{u}$. It is evident that $s_{\max }-s_{0}$ does depend on $\tau_{g}$ only through $\theta$. Panel b): $s_{\max }-s_{0}$ (given as curve parameter) as a function of initial supersaturation $s_{0}$ and $\theta$.

allows to write the differential Eq. (5) in the following form:

$\frac{d s}{d t}=\frac{1+s}{\tau_{u}}-\frac{s}{\widetilde{\tau_{g}}(t)}$.

Introducing the abbreviation $a(t)=\tau_{u}^{-1}-\widetilde{\tau_{g}}(t)^{-1}$, the formal solution of the differential equation is

$s(t)=e^{\int_{0}^{t} a\left(t^{\prime}\right) d t^{\prime}} \int_{0}^{t} \tau_{u}^{-1} e^{-\int_{0}^{t^{\prime}} a\left(t^{\prime \prime}\right) d t^{\prime \prime}} d t^{\prime}+s_{0} e^{\int_{0}^{t} a\left(t^{\prime}\right) d t^{\prime}}$

where the integrals under the exponentials are

$\int_{0}^{t} a\left(t^{\prime}\right) d t^{\prime}=\frac{t}{\tau_{u}}-\frac{t}{\tau_{g}}+\frac{1-e^{-b t / \tau_{g}}}{b}$.

For $t=0$ we have $s(0)=s_{0}$ and for $t \rightarrow \infty, s(t)$ approaches asymptotically the limiting value $s_{\infty}=\tau_{g} /\left(\tau_{u}-\tau_{g}\right)$, provided $\tau_{g} / \tau_{u}<1$. Of course, the solution explodes to infinity, that is, homogeneous nucleation will occur for sure if $\tau_{g} / \tau_{u} \geq 1$

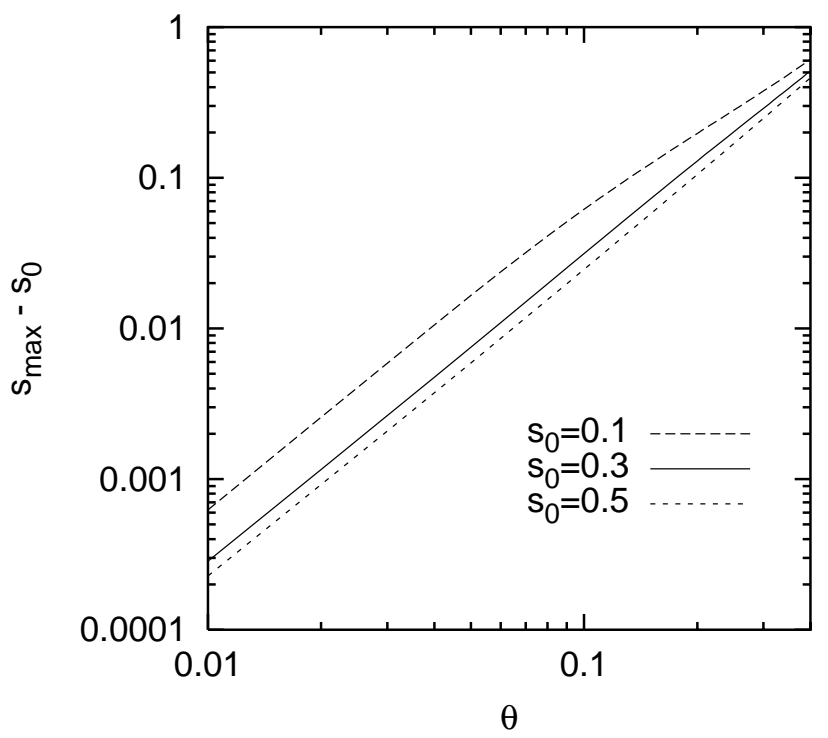

Fig. 7. $s_{\max }-s_{0}$ vs. $\theta=\tau_{g} / \tau_{u}$ for various values of initial supersaturation $s_{0}$. The three curves can be fitted very well with quadratic power functions (i.e. parabolas).

Figure 5 shows some typical curves $s(t)$ for an updraft time scale of $2 \mathrm{~h}$ (typical for $10 \mathrm{~cm} / \mathrm{s}$ uplift), an initial supersaturation $s_{0}=0.3$ and various values of the growth time scale $\tau_{g}$. The most important feature to look at is the initial hump in the curves with a moderately small growth time scale. In such situations homogeneous nucleation becomes dominant when the maximum $s_{\max }$ is higher than the critical supersaturation for homogeneous nucleation. Therefore, in order to determine this maximum for various combinations of $\left\{\tau_{u}, \tau_{g}, s_{0}\right\}$, I have performed further numerical integrations of the differential Eq. (11).

First, one can note that it is useful to introduce the ratio $\theta$ of the two timescales, i.e. $\theta=\tau_{g} / \tau_{u}$. Obviously it suffices to study the range $\theta \in[0,1)$. Figure 6 a shows that the maximum supersaturation $s_{\max }$ does depend on the growth time scale only via the ratio $\theta$, and that $s$ max will normally be high enough to allow homogeneous nucleation already for the quite moderate value $\theta=0.4$. The calculations have been performed for $\tau_{u}=2 \mathrm{~h}$ and $s_{0}=0.3$. Figure $6 \mathrm{~b}$ shows that the difference between the maximum and initial supersaturation depends slightly on the initial value. For parameterisation purposes for large scale models I would neglect this dependence. Figure 7 shows by means of a $\log -\log$ plot that $s_{\max }-s_{0}$ is a power function of $\theta$; indeed, $s_{\max }-s_{0}=f \theta^{2}$ is a very good approximation for the curves. The prefactor $f$ depends on both $s_{0}$ and $b$ in Eq. (8), hence on temperature. For the following, it should be considered a tunable parameter, and I found the best match between boxmodel calculations and the analytical approximation by setting

$$
f(T)=10^{4-0.02 T} .
$$


$\mathrm{s}_{0}=0.3, \mathrm{p}=250 \mathrm{hPa}, \mathrm{w}=\mathrm{var}$

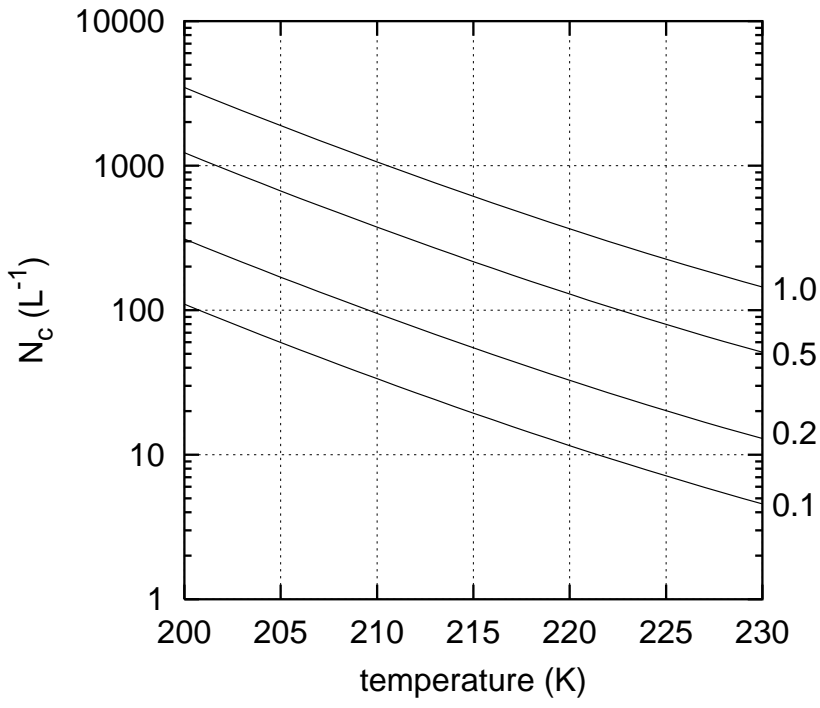

Fig. 8. Critical concentration of heterogeneous ice nuclei as a function of temperature for various updraft speeds (in $\mathrm{m} / \mathrm{s}$, given as curve parameter). The curves are computed from Eq. (21) with pressure of $250 \mathrm{hPa}$ and initial supersaturation of 0.3 .

The exponent of $\theta$ does not depend on $s_{0}$ and neither on $b$.

Thus, one can set up the following criterion: If the supersaturation can increase to the threshold value for homogeneous nucleation, $s_{\text {hom }}$, the latter will dominate in cirrus formation, that is, much more ice crystals will be produced by homogeneous than by heterogeneous nucleation. Whether $s_{\text {max }}$ will reach such a high value depends on the supersaturation necessary for heterogeneous nucleation, $s_{0}$, on temperature (since $s_{\text {hom }}$ depends linearly on $T$ ), and on the ratio of the relevant time scales, $\tau_{g} / \tau_{u}$. For checking the criterion one computes $s_{\max } \approx f(T)\left(\tau_{g} / \tau_{u}\right)^{2}+s_{0}$.

Finally, I derive a formula for the limiting case where $s_{\max }=s_{\text {hom }}(T)$. First, I define the threshold supersaturation for homogeneous nucleation as that value where one ice crystal per cubic metre will be formed in an uplifting airmass. From the boxmodel calculations I find

$s_{\text {hom }}(T)=2.193-7.47 \times 10^{-3} T$,

where $T$ is in K. Next we need an expression for the growth time scale (see above). The coefficient of diffusion of vapour in air, $D$, can be parameterised as:

$D=2.11 \times 10^{-5}\left(\frac{T}{T_{0}}\right)^{1.94}\left(\frac{p_{0}}{p}\right)$

with $D$ in $\mathrm{m}^{2} / \mathrm{s}$ (Pruppacher and Klett, 1978). Here, $T_{0}=$ $273.15 \mathrm{~K}, p_{0}=101325 \mathrm{~Pa}$, and $p$ is air pressure.
Assuming that the initial supersaturation $s_{0}$ is transferred completely into $N$ spherical ice crystals of equal size, their radius would be

$r_{0}=\left(\frac{3 s_{0} e^{*}(T)}{4 \pi N R_{v} T \rho_{i}}\right)^{1 / 3}$,

with the bulk density of ice $\rho_{i}=900 \mathrm{~kg} / \mathrm{m}^{3}$. If constant numbers are collected, the growth time scale can then be written in the following form:

$\tau_{g}^{-1}=1.40 \times 10^{-6} T^{1.61} p^{-1}\left[s_{0} e^{*}(T)\right]^{1 / 3} N^{2 / 3}$.

(All quantities in SI units). In a similar way it is possible to write an expression for the updraft time scale:

$\tau_{u}^{-1}=59.9 w T^{-2}$.

Now, the condition that homogeneous nucleation does not get effective is

$f(T)\left(\tau_{g} / \tau_{u}\right)^{2}+s_{0}<2.193-7.47 \times 10^{-3} T$.

Inserting the expressions for the time scales, and solving for the ice crystal number density, $N$, yields a critical number density $N_{c}$, when an equal sign is set in Eq. (20). This is:

$N_{c}=\frac{2.81 \times 10^{11} f(T)^{3 / 4} w^{3 / 2} p^{3 / 2}}{T^{5.415}\left[s_{0} e^{*}(T)\right]^{1 / 2}\left(s_{\mathrm{hom}}(T)-s_{0}\right)^{3 / 4}}$.

(Again, everything in SI units, i.e. $\mathrm{m}^{-3}, \mathrm{~m} / \mathrm{s}, \mathrm{K}$, and $\mathrm{Pa}$ ). The critical number density $N_{c}$ marks the transition region between homogeneous and heterogeneous cirrus formation. It should be understood as a rough estimate. This means that ice production will be dominated by heterogeneous processes if the concentration of heterogeneous ice nuclei exceeds $N_{c}$; in turn, it will be dominated by homogeneous nucleation if $N$ is smaller than the critical value $N_{c}$ by about half an order of magnitude or even smaller.

As Eq. (21) shows, the sensitivity of the critical concentration of heterogeneous ice nuclei, $N_{c}$, to changes of temperature and updraft speed are much more important than those to changes of either $s_{0}$ or $p$ (although $p$ has also the power $3 / 2$; but the relative variation of $p$ in the upper troposphere is generally small compared to variations of $w$ ). The dependences of $N_{c}$ on temperature and updraft speed is illustrated in Fig. 8.

\section{Summary and conclusions}

In this study I have investigated the transition between cirrus formation due to heterogeneous freezing on the one hand and homogeneous freezing on the other. The study was performed by means of boxmodel simulations of the freezing of a certain type of heterogeneous ice nuclei (aerosol particles that freeze heterogeneously below the critical humidity for homogeneous nucleation). For these I have chosen an internally mixed aerosol consisting of aqueous solution droplets 
of sulfuric acid where a fraction of these droplets bears an inclusion of soot. It was assumed as a working hypothesis that such an aerosol freezes according to the parameterisation given by DeMott et al. (1997). The aerosol cloud was situated in an uplifting and thereby adiabatically cooling airmass where it eventually formed ice crystals. The initial temperature of all simulations was $-53^{\circ} \mathrm{C}$ or lower.

The boxmodel simulations have shown that the transition between homogeneously dominated and heterogeneously dominated cirrus formation occurs over a range of heterogeneous ice nucleus concentration of about one order of magnitude. This transition can in principle be characterised by a critical concentration of heterogeneous ice nuclei which depends in particular on temperature and updraft speed. From the box model simulations it was possible to determine critical soot concentrations of the order $0.01-0.1 \mathrm{ng} \mathrm{m}^{-3}$. However, several uncertainties exist in the derivation of the critical soot concentrations. First, the precise mechanism by which ice germs are formed on soot surfaces is currently unknown. The parametrisation I have used for heterogeneous nucleation (DeMott et al., 1997) is a simple extrapolation of results DeMott (1990) has obtained for water droplets with soot inclusions between $-25^{\circ} \mathrm{C}$ and $-40^{\circ} \mathrm{C}$ to sulfuric acid solution droplets with inclusions and to temperatures below $-53^{\circ} \mathrm{C}$. This is a bold procedure that must be viewed with caution. Second, I have used a specific soot surface that is in the lower range of currently accepted values. Higher specific soot surfaces would translate into lower critical soot concentrations. Third, it turned out that the temperature dependence of water vapour saturation pressure and of the deposition coefficient (more exactly: details of the initial growth of small ice crystals, see also Gierens et al., 2003) are as important as the surface number density of active nucleation sites for the determination of the critical soot concentration. Their values resulting from the simulations should therefore at best considered estimates and not be taken as exact quantities.

The boxmodel simulations suggested to consider the temporal evolution of ice supersaturation after an assumed heterogeneous freezing event at an initial supersaturation, $s_{0}$, to be crucial for the question whether homogeneous nucleation can later take over cirrus formation or not. An analytical estimate has been derived that provides the critical concentration of ice nuclei as a function of temperature, updraft speed, ambient pressure, and $s_{0}$. This formula can be used for simple decision measures in cirrus parametrisations of large scale models, of which nucleation mode should be switched on and which should be switched off.

In stronger updrafts it needs generally higher concentrations of heterogeneous ice nuclei to suppress homogeneous nucleation. I expect, in agreement with results of earlier simulations by others, that heterogeneous nucleation is mostly unimportant for updrafts stronger than $w=20 \mathrm{~cm} \mathrm{~s}^{-1}$. However, in young aircraft plumes or otherwise heavily polluted areas it is possible to reach higher concentrations of heterogeneous ice nuclei (e.g. soot). For example, a modern jet aircraft engine with a specific soot emission of $0.02 \mathrm{~g}$ per $\mathrm{kg}$ kerosene burnt (Schumann, 2002), assuming a fuel flow of $0.8 \mathrm{~kg} \mathrm{~s}^{-1}$ and a flight speed of $250 \mathrm{~m} \mathrm{~s}^{-1}$ can yield a soot concentration in the first second after emission of about $10 \mathrm{ng} \mathrm{m}^{-3}$, which is much higher than the critical values listed above. Thus, cases with $C_{\mathrm{soot}} \approx 1 \mathrm{ng} \mathrm{m}^{-3}$ in internal mixture are not impossible in the atmosphere, and can probably be produced in the northern hemispheric tropopause region by aviation (Rahmes et al., 1998). In such heavily polluted cases homogeneous nucleation would be suppressed until updrafts of about $1 \mathrm{~m} \mathrm{~s}^{-1}$ or so are reached. Rahmes et al. (1998) have computed that the 1992 aviation produced a soot concentration above $10^{-2} \mathrm{ng} \mathrm{m}^{-3}$ in a considerable atmospheric volume in the northern hemisphere. Thus it cannot be excluded that heterogeneous nucleation is much more important for cirrus formation in the northern hemisphere than anywhere else. In fact, recent lidar measurements of cirrus clouds in both northern and southern midlatitudes suggest that just this is the case (Immler and Schrems, 2002).

If the concentration of heterogeneous ice nuclei is just above its critical value, the corresponding heterogeneously formed cirrus cloud will be much optically thinner (perhaps even subvisible) than a cirrus formed homogeneously, because much less ice crystals are produced via heterogeneous nucleation just above the threshold than via the homogeneous process. The clouds get, however, optically thicker again with increasing concentration of heterogeneous ice nuclei although they generally will be less optically thick than those formed homogeneously. Thus, over polluted regions there may be a higher coverage of cirrus clouds (because of the lower formation threshold), but the clouds will probably be thinner. An exception of this rule is the formation of condensation trails because there the concentration of heterogeneous ice nuclei is by many orders of magnitude higher than in the background atmosphere. Cirrus optical depths in regions with a heavy load of air traffic therefore may be on the average larger than in other polluted regions of the northern hemisphere.

Acknowledgements. This work has been performed for the project "Dünner Zirrus" (thin cirrus) which is financed by the Deutsche Forschungsgemeinschaft under grant Gi 333/1-1. It contributes also to the project PAZI (Partikel aus Flugzeugtriebwerken und ihr Einfluss auf Kondensstreifen, Zirruswolken und Klima), funded by the Strategiefonds of the Helmholtz-Gemeinschaft.

\section{References}

DeMott, P. J.: An exploratory study of ice nucleation by soot aerosols, J. Appl. Meteorol., 29, 1072-1079, 1990.

DeMott, P. J., Rogers, D. C., and Kreidenweis, S. M.: The susceptibility of ice formation in upper tropospheric clouds to insoluble aerosol components, J. Geophys. Res., 102, 19575-19584, 1997. 
DeMott, P. J., Chen, Y., Kreidenweis, S. M., Rogers, D.C., and Sherman, D. E.: Ice formation by black carbon particles, Geophys. Res. Lett., 26, 2429-2432, 1999.

Fahey, D. W. and Schumann, U.: Aviation-produced aerosols and cloudiness, in: Aviation and the global atmosphere, (Eds) Penner, J. E., Lister, D. H., Griggs, D. J., Dokken, D. J., and McFarland, M., IPCC Special report, Cambridge University Press, 65120, 1999.

Gierens, K. M.: Numerical simulations of persistent contrails, J. Atmos. Sci., 53, 3333-3348, 1996.

Gierens, K.M., Schumann, U., Smit, H.G.J., Helten, M., and Zängl, G.: Determination of humidity and temperature fluctuations based on MOZAIC data and parametrization of persistent contrail coverage for general circulation models, Ann. Geophysicae, 15, 1057-1066, 1997.

Gierens, K. M. and Ström, J.: A numerical study of aircraft induced ice cloud formation, J. Atmos. Sci., 55, 3253-3263, 1998.

Gierens, K., Schumann, U., Helten, M., Smit, H., and Wang, P.-H.: Ice-supersaturated regions and sub visible cirrus in the northern midlatitude upper troposphere, J. Geophys. Res., 105, $22743-$ $22754,2000$.

Gierens, K. M., Monier, M., and Gayet, J.-F.: The deposition coefficient and its role for cirrus clouds, J. Geophys. Res., 108(D2), 4069, doi: 10.1029/2001JD001558, 2003.

Heymsfield, A. J. and Sabin, R. M.: Cirrus crystal nucleation by homogeneous freezing of solution droplets, J. Atmos. Sci., 46, 2252-2264, 1989.

Heymsfield, A. J. and Miloshevich, L. M.: Homogeneous ice nucleation and supercooled liquid water in orographic wave clouds, J. Atmos. Sci., 50, 2335-2353, 1993.

Immler, F. and Schrems, O.: LIDAR measurements of cirrus clouds in the northern and southern midlatitudes during INCA $\left(55^{\circ} \mathrm{N}, 53^{\circ} \mathrm{S}\right)$ : A comparative study, Geophys. Res. Lett., 29, 10.1029/2002GL015077, 2002.

Jensen, E. J. and Toon, O. B.: Ice nucleation in the upper troposphere: Sensitivity to aerosol composition and size distribution, temperature, and cooling rate, Geophys. Res. Lett., 21, 20192022, 1994.

Jensen, E. J. and Toon, O. B.: The potential impact of soot particles from aircraft on cirrus clouds, Geophys. Res. Lett., 24, 249-252, 1997.

Kärcher, B. and Lohmann, U.: A parameterization of cirrus cloud formation: Homogeneous freezing of supercooled aerosols, J. Geophys. Res., 107, 10.1029/2001JD000470, 2002.

Kärcher, B., Peter, T., Biermann, U.M., and Schumann, U.: The initial composition of jet condensation trails, J. Atmos. Sci., 53, 3066-3083, 1996.

Koenig, L. R.: Numerical modelling of ice deposition, J. Atmos.
Sci., 28, 226-237, 1971.

Koop, T., Luo, B. Tsias, A., and Peter, T.: Water activity as the determinant for homogeneous ice nucleation in aqueous solutions, Nature, 406, 611-614, 2000.

Kristensson, A., Gayet, J.-F., Ström, J., and Auriol, F.: In situ observations of a reduction in effective crystal diameter in cirrus clouds near flight corridors, Geophys. Res. Lett., 27, 681-684, 2000.

Marenco, A., Thouret, V., Nedelec, P., Smit, H., Helten, M., Kley, D., Karcher, F., Simon, P., Law, K., Pyle, J., Poschmann, G., von Wrede, R., Hume, C., and Cook, T.: Measurement of ozone and water vapor by Airbus in-service aircraft: The MOZAIC airborne program, an overview, J. Geophys. Res., 103, $25631-$ $25642,1998$.

Pruppacher, H. R. and Klett, J. D.: Microphysics of clouds and precipitation. D. Reidel publishing company, Dordrecht (NL), XV, 714 pp., 1978.

Rahmes, T.F., Omar, A. H., and Wuebbles, D. J.: Atmospheric distributions of soot particles by current and future aircraft fleets and resulting radiative forcing on climate, J. Geophys. Res., 103, $31657-31667,1998$.

Sassen, K. and Dodd, G.C.: Homogeneous nucleation rate for highly supercooled cirrus cloud droplets, J. Atmos. Sci., 45, 1357-1369, 1988.

Sassen, K. and Benson, S.: Ice nucleation in cirrus clouds: A model study of the homogeneous and heterogeneous modes, Geophys. Res. Lett., 27, 521-524, 2000.

Sausen, R., Gierens, K. Ponater, M., and Schumann, U.: A diagnostic study of the global distribution of contrails, Part I: Present day climate, Theor. Appl. Climatol., 61, 127-141, 1998.

Schumann, U.: Contrail cirrus, in: Cirrus, (Eds) Lynch, D., Sassen, K., O'C. Starr, D., and Stephens, G., Oxford University Press, Oxford, United Kingdom, 231-255, 2002.

Spice, A., Johnson, D. W., Brown, P.R. A., Darlison, A. G., and Saunders, C.P.R.: Primary ice nucleation in orographic cirrus clouds: A numerical simulation of the microphysics, Q. J. R. Meteorol. Soc., 125, 1637-1667, 1999.

Ström, J. and Ohlsson, S.: In situ measurements of enhanced crystal number densities in cirrus clouds caused by aircraft exhaust, J. Geophys. Res., 103, 11 355-11 361, 1998.

Vali, G.: Nucleation terminology, Bull. Amer. Meterol. Soc., 66, 1426-1427, 1985.

Wang, P.-H., Minnis, P., McCormick, M. P., Kent, G. S., and Skeens, K. M.: A 6-year climatology of cloud occurrence frequency from Stratospheric Aerosol and Gas Experiment II observations (1985-1990), J. Geophys. Res., 101, 29 407-29429, 1996.

Young, K. C.: Microphysical processes in clouds, Oxford University Press, Oxford, XV, 427 pp., 1993. 